Copyright (@ 2009 Institute of Electrical and electronics Engineers, Inc.

All Rights reserved.

Personal use of this material, including one hard copy reproduction, is permitted.

Permission to reprint, republish and/or distribute this material in whole or in part for any other purposes must be obtained from the IEEE.

For information on obtaining permission, send an e-mail message to stds-igr@ieee.org.

By choosing to view this document, you agree to all provisions of the copyright laws protecting it.

Individual documents posted on this site may carry slightly different copyright restrictions.

For specific document information, check the copyright notice at the beginning of each document. 


\title{
Variable Frequency Control of the Zero-Voltage Switching Two-Inductor Boost Converter
}

\author{
Quan Li and Peter Wolfs \\ Central Queensland University \\ Rockhampton Mail Center, QLD 4702, Australia
}

\begin{abstract}
The two-inductor boost converter has been previously presented in a Zero-Voltage Switching (ZVS) form where the transformer leakage inductance and the MOSFET output capacitance can be utilized as part of the resonant elements. In many applications, such as Maximum Power Point Tracking (MPPT) in grid interactive photovoltaic systems, the resonant converter is required to operate with variable input output voltage ratios. This paper studies the variable frequency control of the ZVS two-inductor boost converter to secure an adjustable output voltage range while maintaining resonant switching transitions. The design method of the resonant converter is thoroughly investigated and explicit control functions relating the circuit timing factors and the voltage gain for a $200 \mathrm{~W}$ converter are established. Three sets of theoretical, simulation and experimental waveforms are provided for specific operating points. A variation of the basic circuit, the resonant converter with a voltage clamp, which is capable of operating with a wider output voltage range but a lower switch voltage stress, is also given at the end of the paper.
\end{abstract}

\section{INTRODUCTION}

The two-inductor boost converter was developed by applying the duality principle to the half bridge converter and is classified as a boost derived converter [1]. As the converter has a lower switch conduction loss and a full utilization of the transformer, it has found intensive applications where low input voltages are required to be converted to high output voltages such as grid interactive photovoltaic (PV) converters and uninterrupted power supplies [2]-[6].

However, one significant barrier on the way to increase the switching frequency of the two-inductor boost converter is the transformer leakage inductance, which causes higher switch voltage stress and lower converter efficiency. Therefore, the resonant two-inductor boost converter has been developed as shown in Fig. 1 [7]. The resonant converter is able to absorb the transformer leakage inductance and the MOSFET output capacitance into the resonant tank and the Zero-Voltage Switching (ZVS) condition can be achieved. Theoretically, the switching losses are removed and higher efficiencies can be obtained under high switching frequencies.

The ZVS two-inductor boost converter is well suited to the voltage boosting dc-dc conversion in PV converters. Most often, Maximum Power Point Tracking (MPPT) is needed in PV systems and the converter is required to produce variable input output voltage ratios. It has been proposed that the variable frequency control technique can be applied to the resonant converters to cater different load conditions and maintain the resonant conditions [8], [9].

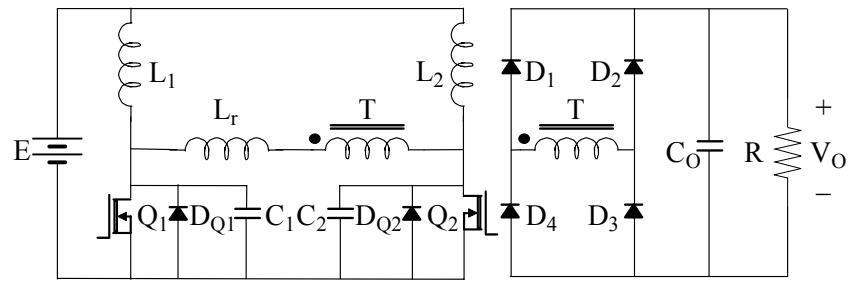

Fig. 1. ZVS two-inductor boost converter

This paper studies the variable frequency operation of the resonant two-inductor boost converter, which has an input voltage of $20 \mathrm{~V}$, a maximum output of $340 \mathrm{~V}$ and a $200 \mathrm{~W}$ rating. The state analysis of the converter is presented and two operational regions are identified. For each region, surfaces relating the transformer primary voltage to the circuit parameters are presented. A full set of design equations are provided and explicit control functions are obtained numerically through the MATLAB program. The theoretical, simulation and experimental waveforms at the selected operating points are given and they agree well. A simple variation of the basic topology with the additional voltage clamp is briefly discussed at the end of the paper. The converter with the voltage clamp is able to achieve a wider output voltage range and a lower switch voltage stress.

\section{VARIABLE FREQUENCY OPERATION}

The resonance of the converter can be analysed using the equivalent circuit shown in Fig. 2. $\mathrm{L}_{\mathrm{r}}$ is the effective resonant inductor and $\mathrm{C}_{1}$ and $\mathrm{C}_{2}$ are the effective resonant capacitors. $\mathrm{D}_{\mathrm{Q} 1}$ and $\mathrm{D}_{\mathrm{Q} 2}$ are embedded reverse body diodes of the MOSFETs. The current source $\mathrm{I}_{0}$ models $\mathrm{L}_{1}$ or $\mathrm{L}_{2}$. The voltage source $\mathrm{V}_{\mathrm{d}}$ is the output voltage on the capacitor $\mathrm{C}_{\mathrm{O}}$ reflected to the transformer primary winding and the diode $\mathrm{D}$ corresponds to the diodes in the full bridge rectifier. The arrangement for $V_{d}$ and $D$ in Fig. 2 assumes a positive resonant inductor current $i_{\text {Lr }}$ as illustrated and their polarities reverse when the inductor current becomes negative. Three important parameters are labelled in bold characters in the resonant waveforms of one operation mode shown in Fig. 3. They are respectively:

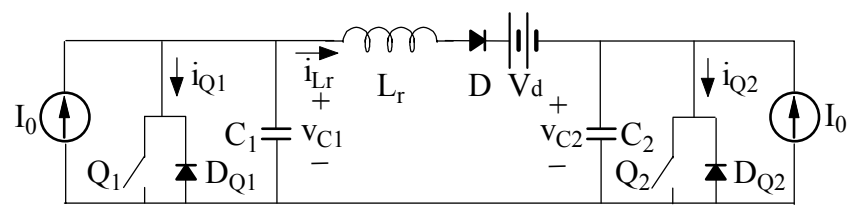

Fig. 2. Equivalent resonant circuit 


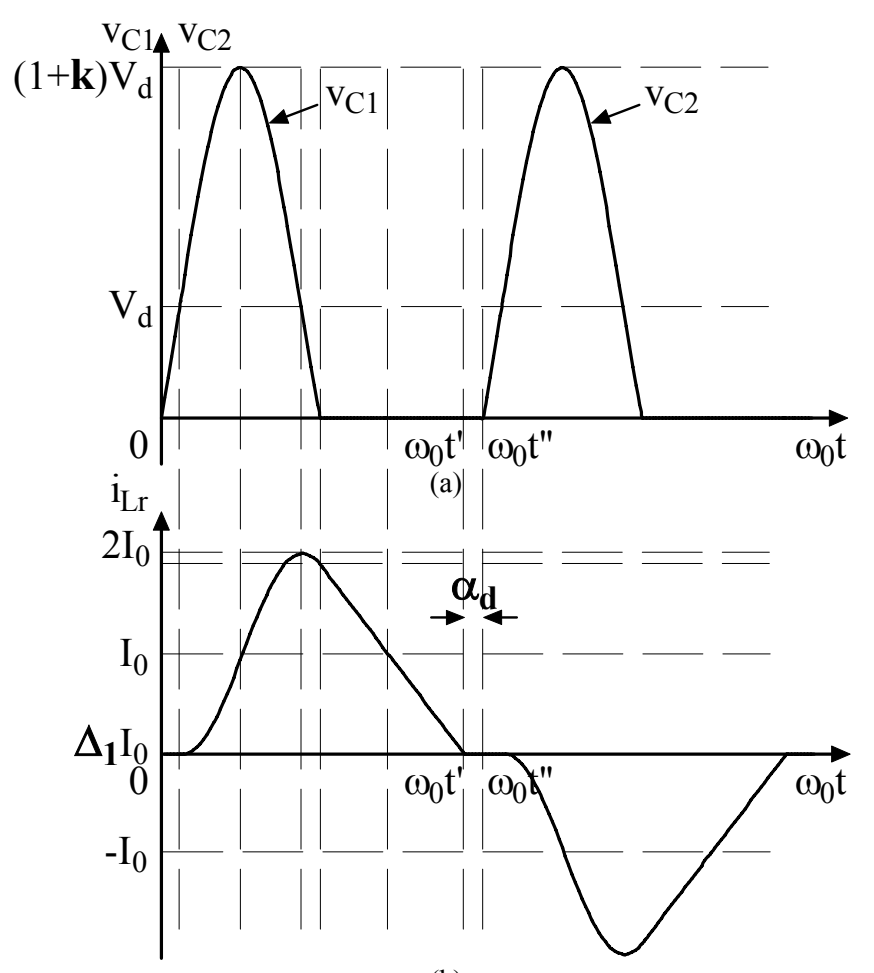

(b)

Fig. 3. Resonant waveforms of one operation mode. (a) Capacitor voltage. (b) Inductor current.

- The timing factor $\Delta_{1}$, which determines the initial resonant inductor current $i_{L r}(0)=-\Delta_{1} I_{0}$ when the MOSFET $Q_{1}$ turns off. The initial inductor current is zero in the operation mode shown in Fig. 3.

- The load factor $\mathrm{k}$, defined by the equation $I_{0} Z_{0}=k V_{d}$, where $Z_{0}=\sqrt{L_{r} / C_{1}}=\sqrt{L_{r} / C_{2}}$ is the characteristic impedance of the resonant tank made up by the resonant inductor and capacitors.

- The delay angle $\alpha_{\mathrm{d}}$, defined as the angle between the instant when the resonant inductor current reaches zero and the instant when the corresponding MOSFET turns off, which respectively corresponds to $\omega_{0} \mathrm{t}$ ' and $\omega_{0} \mathrm{t}$ " in Fig. 3. It can be found that $\alpha_{d}=\omega_{0} t^{\prime \prime}-\omega_{0} t^{\prime}$, where $\omega_{0}$ is the characteristic angular frequency of the resonant tank.

It has been reported that different timing factor $\Delta_{1}$ or delay angle $\alpha_{d}$ and load factor $\mathrm{k}$ values may result in either the continuous or discontinuous operation modes of the resonant two-inductor boost converter [10]. Different operation modes lead to different average values of the absolute resonant inductor or the transformer primary current and therefore different output powers. Therefore the operation of the resonant two-inductor boost converter under variable load condition can be realized by varying the timing factor or the delay angle and the load factor, and thus the switching frequency. Under the variable frequency control, the ZVS condition is maintained.

\section{The Design Method AND the Control FunCtion}

It is established that the ZVS two-inductor boost converter has two operational regions: Region 1 where $\Delta_{1}=0$ and $\alpha_{d} \geq 0$ and Region 2 where $\Delta_{1}>0$ and $\alpha_{d}=0$. It is required that $k \geq 1$ to maintain ZVS conditions in both regions. The discussion on the design equations and the control function in Region 2 is given first. The analysis of the Region 1 operation is very similar and will be given briefly in the due course.

\section{A. Design Equations}

In order to design the converter parameters such as $\mathrm{L}_{\mathrm{r}}, \mathrm{C}_{1}$ or $\mathrm{C}_{2}$ and the transformer turns ratio $\mathrm{n}$ in Region $2, \Delta_{1}$ and $\mathrm{k}$ must be given initially. The design equations are:

$$
\begin{gathered}
E \cdot 2 I_{0}=\frac{V_{O}^{2}}{R} \\
V_{d} \hat{g}_{\Delta}\left(\Delta_{1}, k\right) I_{0}=\frac{V_{O}^{2}}{R} \\
I_{0} Z_{0}=k V_{d} \\
V_{O}=n V_{d}
\end{gathered}
$$

where $\mathrm{E}$ is the input source voltage, $\mathrm{V}_{\mathrm{O}}$ is the output load voltage and $\mathrm{R}$ is the load resistance. Function $\hat{g}_{\Delta}\left(\Delta_{1}, k\right)$ is the ratio of the average of the absolute current in the resonant inductor or the transformer primary to $\mathrm{I}_{0}$ and is determined by two independent variables, $\Delta_{1}$ and $\mathrm{k}$. From (1) to (4), if $\mathrm{E}, \mathrm{V}_{\mathrm{O}}$ and $\mathrm{R}$ are also known, $\mathrm{I}_{0}, \mathrm{~V}_{\mathrm{d}}, \mathrm{Z}_{0}$ and $\mathrm{n}$ can be solved. Then the converter parameters including $L_{r}$ and $\mathrm{C}_{1}$ or $\mathrm{C}_{2}$ can be easily obtained once the switching frequency $\mathrm{f}_{\mathrm{s}}$ is determined.

\section{B. Control Function}

After the values of $\mathrm{L}_{\mathrm{r}}, \mathrm{C}_{1}$ or $\mathrm{C}_{2}$ and $\mathrm{n}$ are calculated through the design equations, the load factor $\mathrm{k}$ is no longer an independent variable deciding $\mathrm{V}_{\mathrm{d}}$ or $\mathrm{V}_{\mathrm{O}}$. Then (2) should be rewritten by replacing $\hat{g}_{\Delta}\left(\Delta_{1}, k\right)$ with $g_{\Delta}\left(\Delta_{1}\right)$ as in (5), where the dependent variable $\mathrm{k}$ is removed:

$$
V_{d} \cdot g_{\Delta}\left(\Delta_{1}\right) \cdot I_{0}=\frac{V_{O}^{2}}{R}
$$

Dividing (5) by (1) and solving for $\mathrm{V}_{\mathrm{d}}$ yield:

$$
V_{d}=\frac{2 E}{g_{\Delta}\left(\Delta_{1}\right)}
$$

Equation (6) is clearly in the format of the control function for the ZVS two-inductor boost converter, relating the transformer primary voltage $\mathrm{V}_{\mathrm{d}}$ to the circuit timing factor $\Delta_{1}$. However, function $g_{\Delta}\left(\Delta_{1}\right)$ cannot be solved 
directly. An indirect method is to maintain the load factor $\mathrm{k}$ as a variable initially in (6) as:

$$
V_{d}=\frac{2 E}{\hat{g}_{\Delta}\left(\Delta_{1}, k\right)}
$$

and then to eliminate it by applying the inherent circuit constraint obtained through (1) to (4):

$$
k=\frac{n^{2} Z_{0}}{R} \cdot \frac{1}{\hat{g}_{\Delta}\left(\Delta_{1}, k\right)}
$$

As the analytical solution of function $\hat{g}_{\Delta}\left(\Delta_{1}, k\right)$ in (7) consists of the inverse triangle functions and presents a significant level of complexity, the understanding of the physical implication of the function becomes impossible. Therefore, function $\hat{g}_{\Delta}\left(\Delta_{1}, k\right)$ is solved numerically by MATLAB program against a range of $\Delta_{1}$ and $\mathrm{k}$ values through the state analysis of the converter, which will be introduced in the design process. The two functions in (8) $h_{1, \Delta}\left(\Delta_{1}, k\right)=k \quad$ and $\quad h_{2, \Delta}\left(\Delta_{1}, k\right)=\frac{n^{2} Z_{0}}{R} \cdot \frac{1}{\hat{g}_{\Delta}\left(\Delta_{1}, k\right)}$ respectively represent a surface in a three-dimensional space with $\Delta_{1}$ and $\mathrm{k}$ as two axes. The inherent relationship of $\Delta_{1}$ and $\mathrm{k}$ can be established by the intersection curve of the two surfaces and is then back substituted to (7) to remove the dependent variable $\mathrm{k}$ and derive the control function in its numerical form. Then the control function $V_{d}=M_{\Delta}\left(\Delta_{1}\right)$ can be obtained by polynomial fitting.

In Region 1, the equations share the same format of their counterparts in Region 2 except that the variable $\Delta_{1}$ needs to be replaced by $\alpha_{d}$ and the subscript $\Delta$ by $\alpha$ to maintain the nomenclatural clarity and consistency.

\section{Design Process}

Before $\mathrm{Q}_{1}$ turns off, both of $\mathrm{Q}_{1}$ and $\mathrm{Q}_{2}$ are closed. At time $t=0, \mathrm{Q}_{1}$ turns off and the converter will move up to four possible states before $\mathrm{Q}_{2}$ turns off as shown in Fig. 4 [10]. The initial conditions for State (a) are $i_{L r}(0)=-\Delta_{1} I_{0}$ and $v_{C 1}(0)=0$. Equations for the capacitor voltage $\mathrm{v}_{\mathrm{C} 1}$ and the inductor current $i_{\mathrm{Lr}}$ in each state are listed in Table I.

As a higher output voltage appears in Region 1, the maximum output voltage, $340 \mathrm{~V}$, must be designed in Region 1. Other parameters used in the converter design are $E=20 \mathrm{~V}$ and $R=576 \Omega$. By performing state analysis with MATLAB program, function $\hat{g}_{\alpha}\left(\alpha_{d}, k\right)$ can be calculated and $\mathrm{V}_{\mathrm{d}}$ in Region 1 can be drawn as a surface against $\alpha_{d}$ and $\mathrm{k}$ in Fig. 5 according to the counterpart of (7). A theoretical maximum peak switch voltage of $200 \mathrm{~V}$ is allowed in the design in order to employ MOSFETs with low forward resistances. From (3) and (13), the peak switch voltage is:

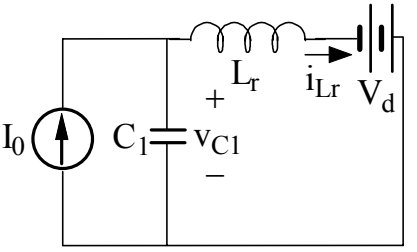

State (a)

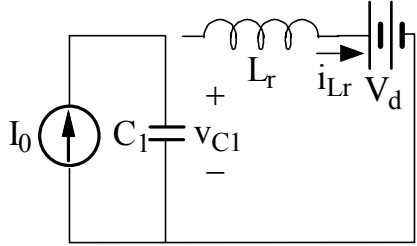

State (b)

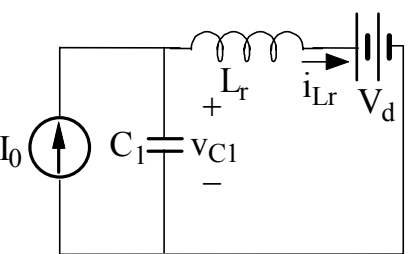

State (c)

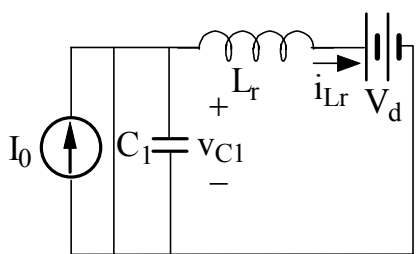

State (d)
Fig. 4. Four possible states

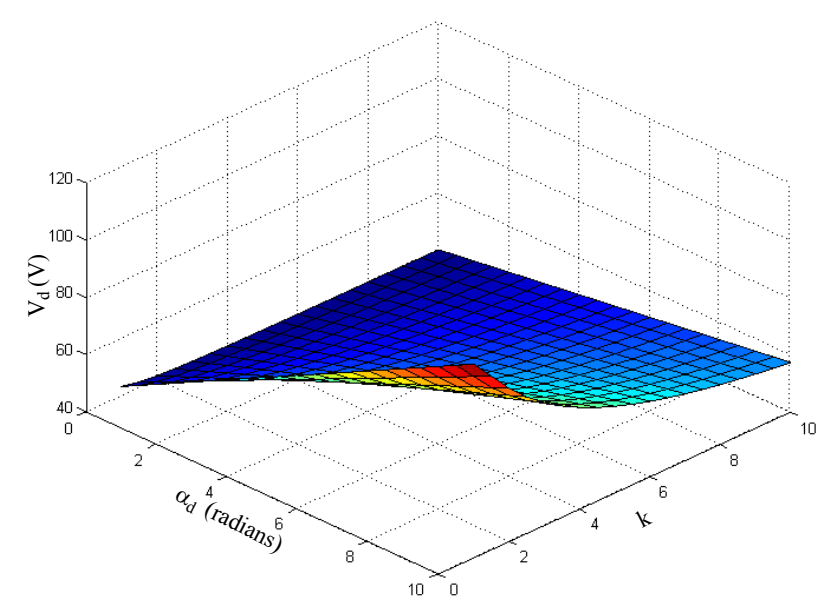

Fig. 5. Surface $V_{d}$ in Region 1

TABLE I

EQUATIONS IN EAch STATE

\begin{tabular}{|c|l|}
\hline State & \multicolumn{1}{|c|}{ Equations } \\
\hline State (a) & $v_{C 1}(t)=\left(1+\Delta_{1}\right) I_{0} Z_{0} \sin \left(\omega_{0} t\right)+V_{d} \cos \left(\omega_{0} t\right)-V_{d}$ \\
\cline { 2 - 3 } $0 \leq t \leq t_{1}$ & $i_{L r}(t)=\frac{V_{d}}{Z_{0}} \sin \left(\omega_{0} t\right)-\left(1+\Delta_{1}\right) I_{0} \cos \left(\omega_{0} t\right)+I_{0}$ \\
\hline State (b) & $v_{C 1}(t)=\frac{I_{0}}{C_{1}}\left(t-t_{1}\right)+v_{C 1}\left(t_{1}\right)$ \\
$t_{1} \leq t \leq t_{2}$ & $i_{L r}(t)=0$ \\
\hline State (c) & $v_{C 1}(t)=I_{0} Z_{0} \sin \omega_{0}\left(t-t_{2}\right)+\left[v_{C 1}\left(t_{2}\right)-V_{d}\right] \cos \omega_{0}\left(t-t_{2}\right)+V_{d}(13)$ \\
$t_{2} \leq t \leq t_{3}$ & $i_{L r}(t)=\frac{v_{C 1}\left(t_{2}\right)-V_{d}}{Z_{0}} \sin \omega_{0}\left(t-t_{2}\right)-I_{0} \cos \omega_{0}\left(t-t_{2}\right)+I_{0}$ \\
\cline { 2 - 2 } & $v_{C 1}(t)=0$ \\
\cline { 2 - 2 } State (d) \\
$t_{3} \leq t \leq t_{4}$ & $i_{L r}(t)=i_{L r}\left(t_{3}\right)-\frac{V_{d}}{L_{r}}\left(t-t_{3}\right)$ \\
\hline
\end{tabular}




$$
V_{Q, \text { peak }}=\left\{1+\sqrt{k^{2}+\left[\frac{v_{C 1}\left(t_{2}\right)}{V_{d}}-1\right]^{2}}\right\} V_{d}
$$

An initial set of design parameters is selected to be $\alpha_{d}=4$ and $k=2.31$. The set of the design equations can be solved and the calculation results are:

- $I_{0}=5.0 \mathrm{~A}$,

- $\hat{g}_{\alpha}\left(\alpha_{d}, k\right)=0.660$,

- $V_{d}=60.6 \mathrm{~V}$,

- $n=5.6$,

- $Z_{0}=27.9 \Omega$,

- $\omega_{0} / f_{s}=24.8$ radians .

The circuit constraint is now applied and the surfaces $h_{1, \alpha}\left(\alpha_{d}, k\right)=k \quad$ and $\quad h_{2, \alpha}\left(\alpha_{d}, k\right)=\frac{n^{2} Z_{0}}{R} \cdot \frac{1}{\hat{g}_{\alpha}\left(\alpha_{d}, k\right)}$ are drawn in Fig. 6. The intersection curve $\mathrm{u}_{\alpha}$ determines the relationship between $\alpha_{d}$ and $\mathrm{k}$, which is substituted to the control function with the dependent variable. Through polynomial fitting, the control function $M_{\alpha}\left(\alpha_{d}\right)$ can be found as:

$$
\begin{aligned}
V_{d}=M_{\alpha}\left(\alpha_{d}\right)= & 0.0079 \alpha_{d}^{3}+0.2124 \alpha_{d}^{2} \\
& +5.4130 \alpha_{d}+41.7942
\end{aligned}
$$

The design process in Region 2 is similar and the surface $\mathrm{V}_{\mathrm{d}}$ is drawn against $\Delta_{1}$ and $\mathrm{k}$ in Fig. 7. The surfaces $h_{1, \Delta}\left(\Delta_{1}, k\right)$ and $h_{2, \Delta}\left(\Delta_{1}, k\right)$ are drawn in Fig. 8. The intersection curve $u_{\Delta}$ determines the relationship between $\Delta_{1}$ and $\mathrm{k}$, which is substituted to (7). Through polynomial fitting, the control function $M_{\Delta}\left(\Delta_{1}\right)$ can be found as:

$$
\begin{aligned}
V_{d}=M_{\Delta}\left(\Delta_{1}\right)= & 0.3005 \Delta_{1}^{3}+0.0221 \Delta_{1}^{2} \\
& -9.0395 \Delta_{1}+41.7931
\end{aligned}
$$

The control functions $M_{\alpha}\left(\alpha_{d}\right)$ and $M_{\Delta}\left(\Delta_{1}\right)$ are respectively drawn in Figs. 9 and 10. Region 1 operation ends when $\alpha_{d}=0, k=1.59$ and $V_{d}=41.8 \mathrm{~V}$. In Region 2 , when $\Delta_{1}$ reaches $2, \mathrm{k}$ reaches 1 , which is the critical border for ZVS operation. At this point, $V_{d}=26.2 \mathrm{~V}$. The switching frequency when $\Delta_{1}=2.0$ and $k=1.00$ is selected to be $500 \mathrm{kHz}$. The characteristic angular frequency of the resonant tank is $4.069 \mathrm{Mrs}^{-1}$ and the switching frequency is $163.9 \mathrm{kHz}$ when $\alpha_{d}=4.0$ and $k=2.31$. The resonant inductance and capacitance can be respectively calculated to be $L_{r}=6.85 \mu \mathrm{H}$ and $C_{1}=C_{2}=8.82 \mathrm{nF}$. Under these converter parameters, the output voltage can be theoretically adjusted between $147 \mathrm{~V}$ and $340 \mathrm{~V}$.

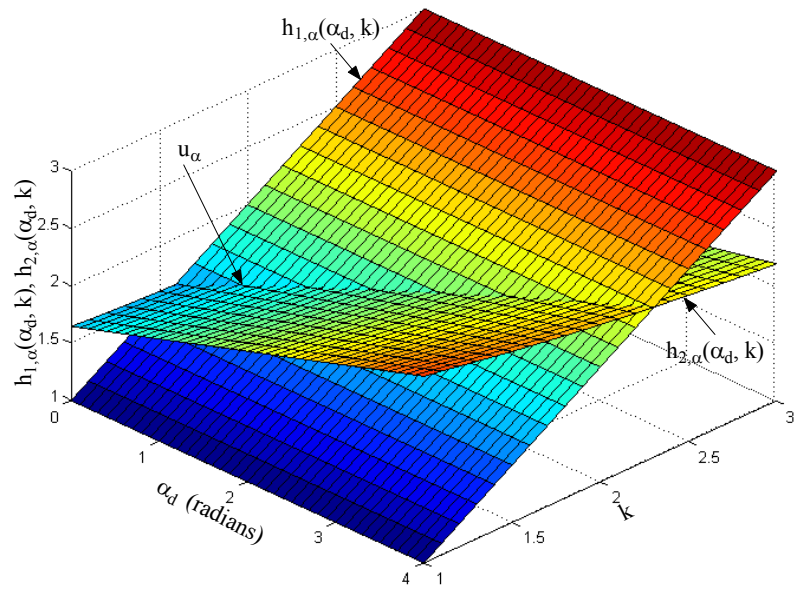

Fig. 6. Surfaces $h_{1, \alpha}\left(\alpha_{d}, k\right)$ and $h_{2, \alpha}\left(\alpha_{d}, k\right)$

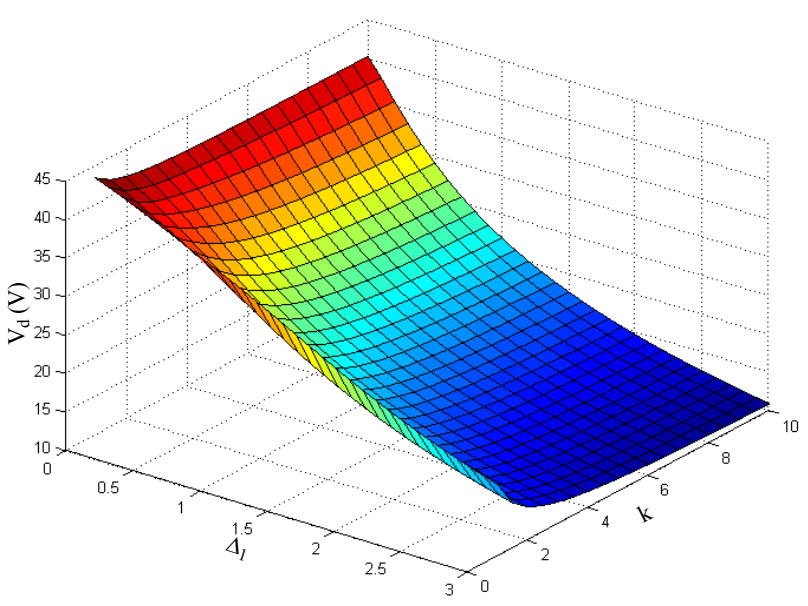

Fig. 7. Surface $V_{d}$ in Region 2

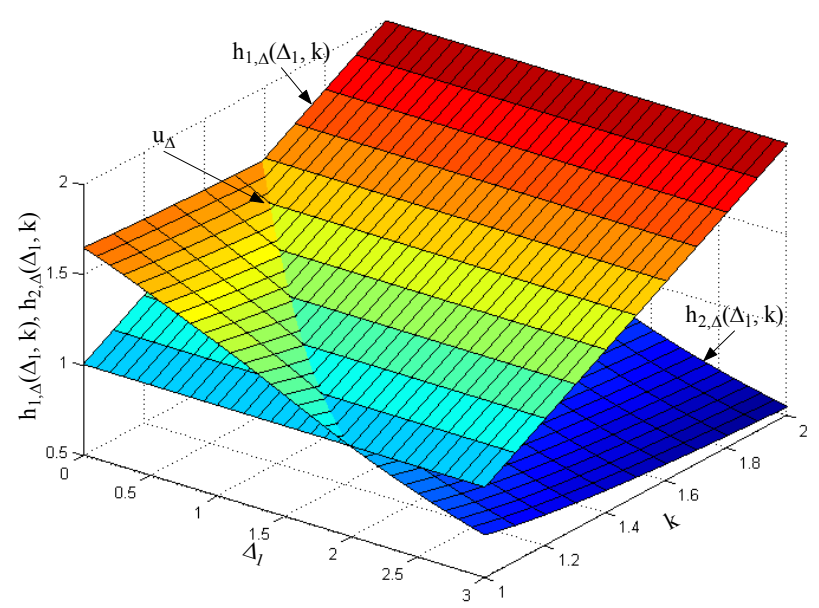

Fig. 8. Surfaces $h_{1, \Delta}\left(\Delta_{1}, k\right)$ and $h_{2, \Delta}\left(\Delta_{1}, k\right)$ 


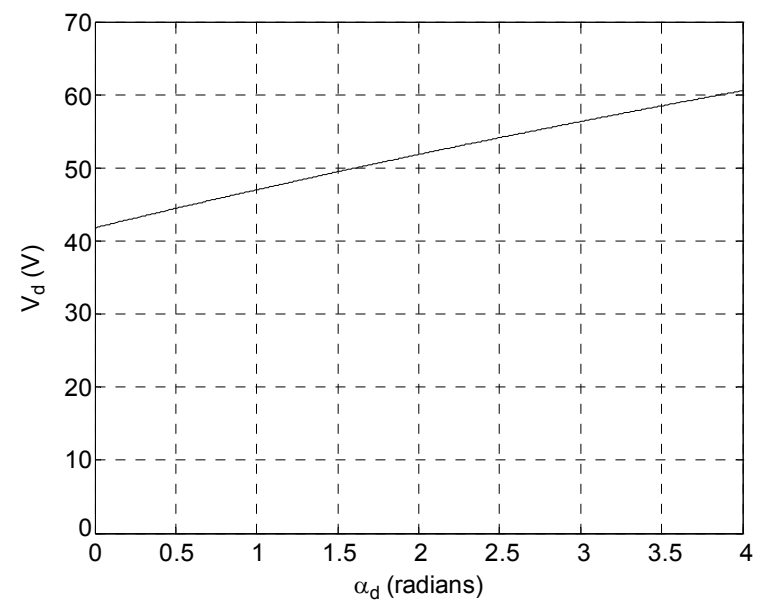

Fig. 9. The control function $M_{\alpha}\left(\alpha_{d}\right)$

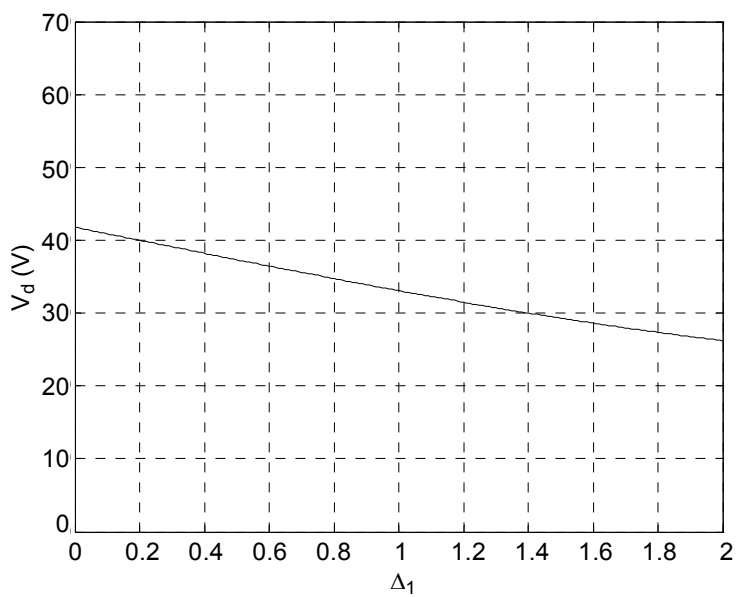

Fig. 10. The control function $M_{\Delta}\left(\Delta_{1}\right)$

\section{The TheORECTICAL AND SimUlation WAVEFormS}

The selected operating points are listed in Table II. It is worth mentioning that the converter operation when $\Delta_{1}=2.0$ and $k=1.00$ is only theoretically achievable as the MOSFETs duty ratio under those circuit parameters is $50 \%$. This is not practically possible considering the delays over the MOSFET turn-on and turn-off transitions. Therefore the waveforms of an operating point with the practically lowest output voltage when $\Delta_{1}=1.6$ and $k=1.09$ are demonstrated instead. The practical output voltage range, $160 \mathrm{~V}$ to $340 \mathrm{~V}$, is slightly narrower than the theoretical one. The theoretical waveforms are generated by plotting the device waveforms according to (9) to (16) and the simulation is performed with SIMULINK.

\section{THE EXPERIMENTAL WAVEFORMS}

The experimental waveforms of the three individual operating points are respectively given in Figs. 17 to 19. From top to bottom, the waveforms are respectively the MOSFET gate voltage, the resonant capacitor voltage and the resonant inductor current. The experimental results agree reasonably well with the theoretical and the simulation ones except that the MOSFET drain source voltage in the simulation and experimental waveforms is slightly higher than that in the theoretical waveforms.

\section{ZVS TWO-INDUCTOR BOOST CONVERTER WITH THE VOLTAGE Clamp}

In designing the variable frequency control of the ZVS two-inductor boost converter, the load factor $\mathrm{k}$ must be small otherwise the voltage stress of the MOSFET will become excessively high according to (17). This constraint inherently results in a very limited output voltage range. In order to operate the converter with a much wider output voltage range under a reasonable MOSFET voltage stress, mechanisms which are able to control the MOSFET voltage below a certain level are required. A simple arrangement is the voltage clamp circuit shown in Fig. 20.

The voltage clamping circuit for each MOSFET consists of one coupled inductor $\mathrm{L}_{1 \mathrm{p}}, \mathrm{L}_{1 \mathrm{~s}}$ or $\mathrm{L}_{2 \mathrm{p}}, \mathrm{L}_{2 \mathrm{~s}}$ and one diode $\mathrm{D}_{\mathrm{L} 1}$ or $\mathrm{D}_{\mathrm{L} 2}$. The turns ratio of the coupled inductor main winding $\mathrm{L}_{1 \mathrm{p}}$ or $\mathrm{L}_{2 \mathrm{p}}$ to the clamp winding $\mathrm{L}_{1 \mathrm{~s}}$ or $\mathrm{L}_{2 \mathrm{~s}}$ is $\mathrm{n}_{\mathrm{L}}: 1$. When the voltage across the main winding of each coupled inductor reaches $n_{L} E$, dot negative, the diode $D_{L 1}$ or $D_{L 2}$ will conduct and this clamps the voltage across the MOSFET to:

$$
V_{c}=\left(1+n_{L}\right) E
$$

The design process of the new converter is similar to the converter without the voltage clamp. Theoretically the peak MOSFET voltage is not determined by the variable $\mathrm{k}$ any more and will remain well below $200 \mathrm{~V}$ if $\mathrm{n}_{\mathrm{L}}$ is small enough according to (20). One potential issue with this converter is, however, the energy circulation in the voltage clamping circuit, which will cause parasitic losses and reduce the converter overall efficiency.

TABLE II

Selected Operating Points

\begin{tabular}{|c|c|c|c|c|c|c|c|c|c|}
\hline $\begin{array}{c}\text { Operating } \\
\text { Point }\end{array}$ & $\Delta_{1}$ & $\begin{array}{c}\alpha_{d} \\
\text { (radians) }\end{array}$ & $k$ & $\begin{array}{c}V_{d} \\
(\mathrm{~V})\end{array}$ & $\begin{array}{c}f_{s} \\
(\mathrm{kHz})\end{array}$ & $\begin{array}{c}\text { MOSFET } \\
\text { Duty Ratio }\end{array}$ & $\begin{array}{c}\text { Operation } \\
\text { Mode }\end{array}$ & $\begin{array}{c}\text { Theoretical } \\
\text { Waveforms }\end{array}$ & $\begin{array}{c}\text { Simulation } \\
\text { Waveforms }\end{array}$ \\
\hline 1 & 0 & 4.0 & 2.31 & 60.6 & 163.9 & 0.838 & Discontinuous & Fig. 11 & Fig. 14 \\
\hline 2 & 0 & 0 & 1.59 & 41.8 & 279.6 & 0.694 & Discontinuous & Fig. 12 & Fig. 15 \\
\hline 3 & 1.6 & 0 & 1.09 & 28.6 & 454.5 & 0.532 & Continuous & Fig. 13 & Fig. 16 \\
\hline
\end{tabular}



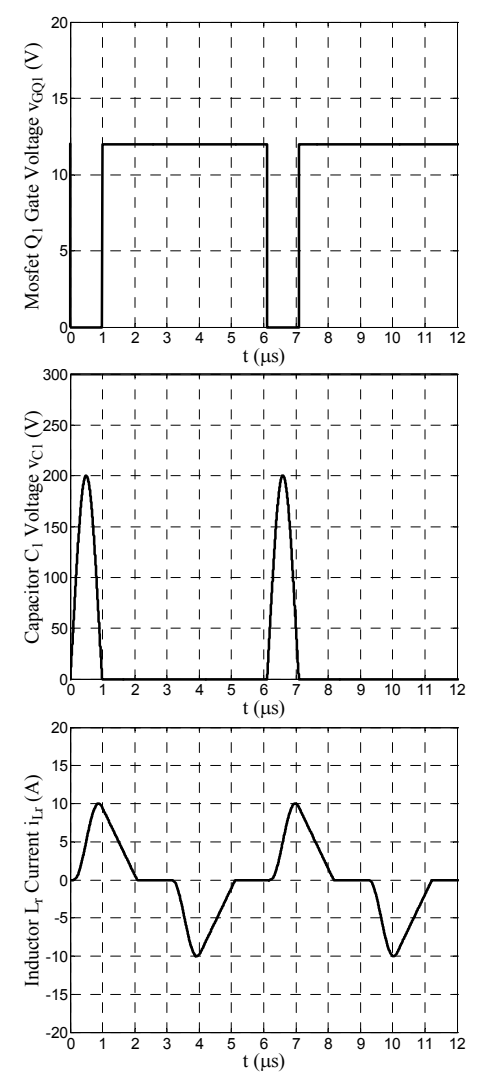

Fig. 11. Theoretical Waveforms
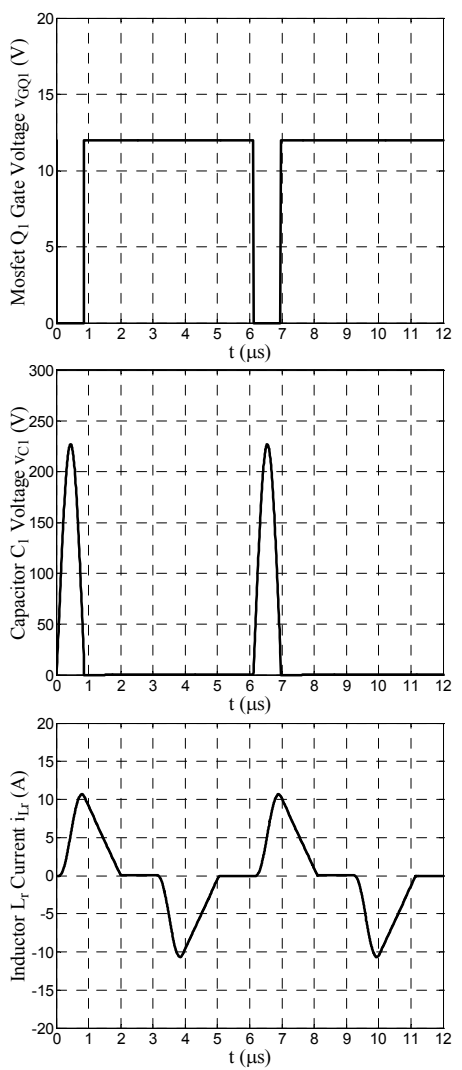

Fig. 14. Simulation Waveforms
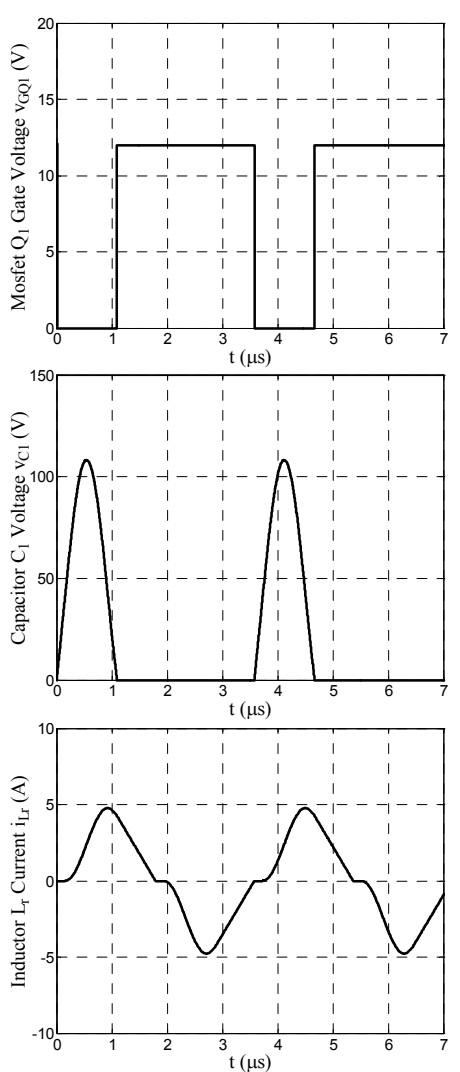

Fig. 12. Theoretical Waveforms
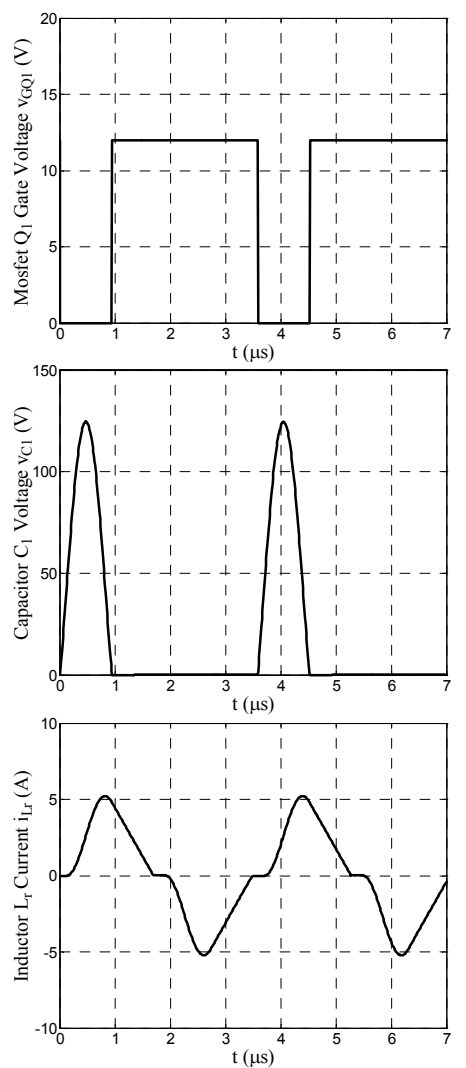

Fig. 15. Simulation Waveforms
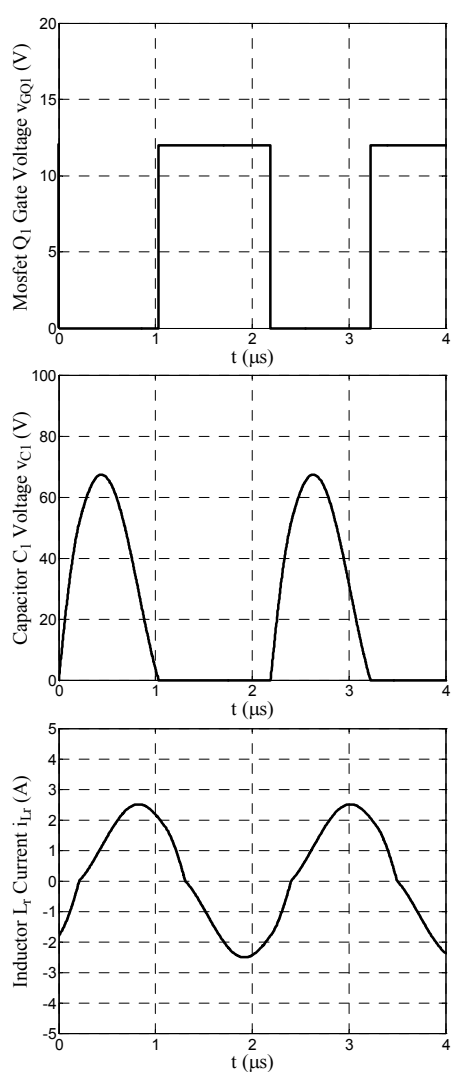

Fig. 13. Theoretical Waveforms
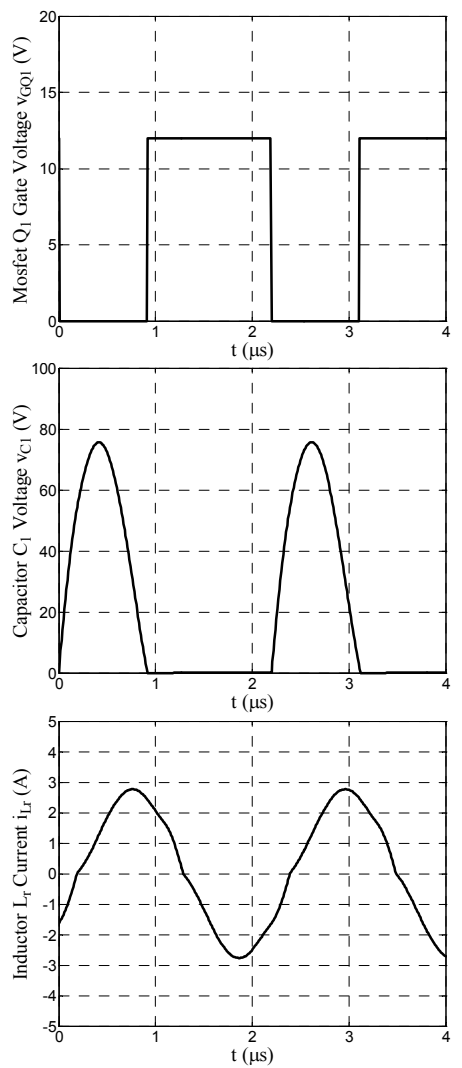

Fig. 16. Simulation Waveforms 


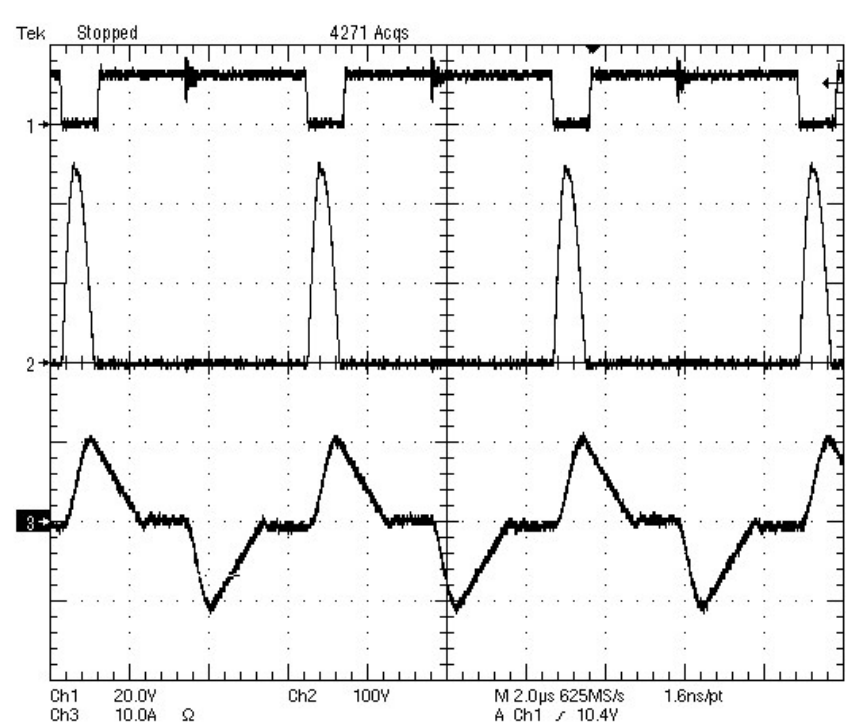

Fig. 17. Experimental Waveforms

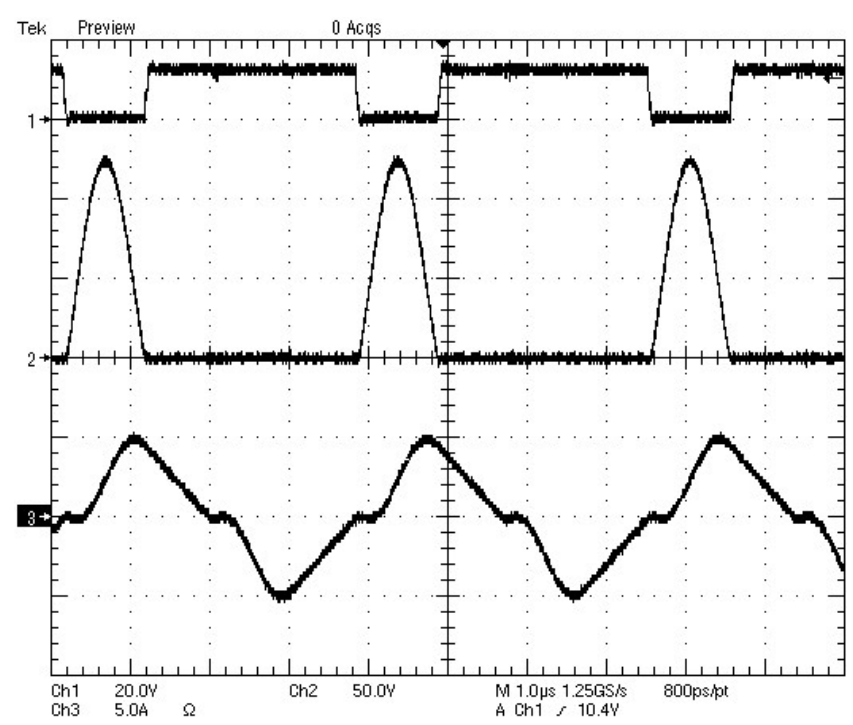

Fig. 18. Experimental Waveforms

\section{CONCLUSIONS}

This paper studies the variable frequency control of the ZVS two-inductor boost converter based on varying the circuit parameters such as the timing factor $\Delta_{1}$ or the delay angle $\alpha_{\mathrm{d}}$. Under the variable frequency control, the resonant converter operates with a variable input output voltage ratio while maintaining the soft-switching conditions. Both the design equations and the control functions are elaborated. Under reasonable switch voltage stresses, the converter is able to achieve an output voltage range from $160 \mathrm{~V}$ to $340 \mathrm{~V}$ while the converter with the voltage clamp is able achieve a wider output voltage range but a lower efficiency may be present due to the power losses in the voltage clamping circuit caused by the circulating energy.

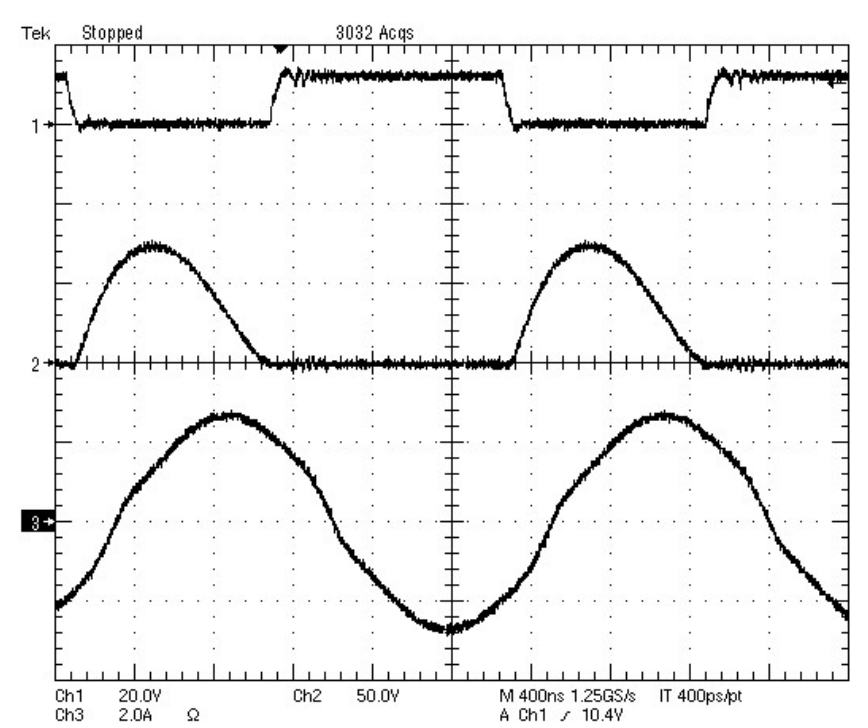

Fig. 19. Experimental Waveforms

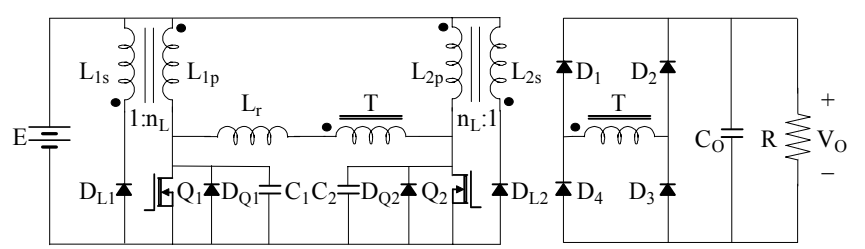

Fig. 20. The ZVS two-inductor boost converter with the voltage clamp

\section{REFERENCES}

[1] P. J. Wolfs, "A current-sourced dc-dc converter derived via the duality principle from the half-bridge converter," IEEE Trans. on Industrial Electronics, Vol. 40, No. 1, pp. 139-144, Feb. 1993.

[2] G. Ivensky, I. Elkin and S. Ben-Yaakov, "An isolated dc-dc converter using two zero current switched IGBTs in a symmetrical topology," in Proc. IEEE PESC, 1994, pp.1218-1225.

[3] W. C. P. De Aragao Filho and I. Barbi, "A comparison between two current-fed push-pull dc-dc converters - analysis, design and experimentation," in Proc. IEEE INTELEC, 1996, pp. 313-320.

[4] J. Kang, "Phase-shifted constant duty cycle converter derived from two-module parallel-input/series-output modularized dual converter," Master Dissertation, Korea Advanced Institute of Science and Technology, Korea, 1999.

[5] Y. Jang and M. M. Jovanovic, "New two-inductor boost converter with auxiliary transformer," IEEE Trans. Power Electronics, Vol. 19, No. 1, pp. 169-175, Jan. 2004.

[6] L. Yan and B. Lehman, "An integrated magnetic isolated twoinductor boost converter: analysis, design and experimentation," IEEE Trans. Power Electronics, Vol. 20, No. 2, pp. 332-342, Mar. 2005.

[7] Q. Li and P. Wolfs, "A resonant half bridge dual converter," in Proc. of Australasian Universities Power Engineering Conference, 2001, pp. 263-268; also Journal of Electrical \& Electronic Engineering Australia, Vol. 22, No. 1, pp.17-23, 2002.

[8] A. C. Lippincott and R. M. Nelms, "A capacitor-charging power supply using a series-resonant topology, constant on-time/variable frequency control, and zero-current switching," IEEE Trans. on Industrial Electronics, Vol. 38, No. 6, pp. 438-447, Dec. 1991.

[9] D. Maksimovic and S. Cuk, "Constant-frequency control of quasiresonant converters," IEEE Trans. on Power Electronics, Vol. 6, No. 1, pp. 141-150, Jan. 1991.

[10] P. Wolfs and Q. Li, "An analysis of a resonant half bridge dual converter operating in continuous and discontinuous modes," in Proc. of IEEE PESC, 2002, pp.1313-1318. 